\title{
COSMOPOLIS DO DIREITO
}

No ultimo numero do Annuario da Associaşão Internacional de Legislação comparada e Economia politica, de Berlim, publicou o Dr. F. Meili, professor de Direito internacional privado na Universidade de $\mathrm{Zu}$ rich, um trabalho-Eine offizielle Heinstätte für das Peregrinenrecht der modernen Welt-do qual colhemos, com viva satisfação, novas forças para a defesa da these, de que nos fizemos incançavel, posto que obscuro patrono: a necessidade da universalisação do direito.

Depois de accentuar que o sentimento geral contemporaneo (der heutige Verkehr) abstrahe dos limites geographicos dos diversos estados, e firma entre os homens effectivo cosmopolitismo; depois de ponderar, que só mediante o conhecimento universal das leis, poderão ser solvidos os conflictos de direitos, determinados pela separação dos homens por estados 
diversos; depois de affirmar que em parte alguma, porém, o diplomata, o legislador, o juiz e o advogado. podem achar um archivo onde encontrem o texto authentico das leis de cada Estado-que mesmo em um unico Estado seria difficil dar com a completa e clara compilação do direito objectivo; depois de relembrar a lamentação (die Klage) de Cicero, relativa ao direito internacional: legum custodiam nullam habemus (i), dizendo que ella até hoje se renova-- passa o illustre professor a nos informar do estado actual daquella indomita aspiração humana, e dos progressos que vai fazendo a grandiosa propaganda universalisadora.

Si está longe ainda de satisfazer aos sofregos a situação de hoje, é todavia certo que a propaganda caminha.

Em Londres não ha siquer uma compilação das leis coloniaes nem no British Museum, ou mesmo no ministerio das Colonias; e si em Paris existe, no ministerio da Justiça, desde I 876, o Comité de législation étrangère, com importante bibliotheca, não ha todavia Estado algum que tenha uma collecção official das leis estrangeiras para serem chronologica e systematicamente traduzidas e publicadas em uma lingua universal. Apenas a Société de législation comparée de Paris traduziu em francez diversas leis, taes como:

I) o Codigo do commercio, o direito cambial, e a lei judiciaria, da Allemanha,

2) o Codigo criminal dos Paizes Baixos,

3) e o da Hungria.

(I) Cicero, de legibus, XX, 46. 
Mas os trabalhos daquella Sociedade, a saber:

I) Annuaire de législation étrangère (contendo lé hoje 22 volumes),

2) Annuaire de législation française (até hoje 3 volumes),

3) Bulletin mensuel (25 volumes)--

não teem muita estimação na Allemanha.

Contam-se, como aproveitaveis á propaganda cosropolișadora do direito, algumas traducções inglezas, iseridas nos Annales of the American Academy of olitical and social science, das constituições de varios sstados (França, Prussia, Italia, Columbia, Mexico).

A Allemanha ainda conta com importantes comilações de leis estrangeiras, devidas unicamente do elo e sacrificio de particulares. São principaes, em ngua allemã: a das leis cambiaes, de O. Borchardt, das leis sobre patentes de invenção, de Gareis, e collecção de obras scientificas estrangeiras sobre ireito criminal, tambem vertidas em allemão.

A Belgica mandou compilar o direito de todos s Estados sobre o casamento, para dar aos seus reresentantes nos paizes estrangeiros base segura na Jlução dos conflictos entre os diversos estatutos sore este ponto.

Muito mais importante, porém, é o accordo a ue, em I 890, chegaram varios estados para a traueção e publicação commum das leis sobre tarifas duaneiras-accordo a que o imperio allemão se bsteve de concorrer.

Para aquelle fim, cuja influencia sobre a univeralisação do direito é da maior intensidade, creou-se 


\section{$-146-$}

um Burcau, com séde em Bruxellas (2). Entraram na convenção os seguintes estados, cuja lista damos integralmente para melhor salientar a compungente aúsencia do Brasil, que naquelle anno ardia na febre da desordenada dictadura militar: a Republica Argentina, Austria-Hungria, Belgica, Bolivia, Chile, o Estado independente do Congo, a Republica de Costa Rica, Dinamarca e suas colonias, Hespanha e suas colonias, os Estados Unidos da America, França e suas colonias, a Grã Bretanha e suas colonias, a India ingleza, Canadá, as Colonias Westaustralianas; o Cabo da Boa Esperança, Natal, a Nova Galles do Sul, a Terra Nova, a Australia do Norte ou Queensland, a Tasmania ou ilha de Diemen, a Nova Fundland e Victoria, Grecia, Guatemala, Haiti, Italia e suas colonias, Mexico, Nicaragua, Paraguay, os Paizes Baixos e suas colonias, Perú, Portugal e suas colonias (3), a Romania, Russia, S. Salvador, Sião, a Suissa, Turquia, Uruguay e Venezuela. Em I 894 entrou na convenção a China. fim:

No art. 2: da Convenção synthetisa-se o seu

«Le but de L'UNion est de publier, à frais communs, et de faire connaître, aussi promptement et aussi exactement que possibie, les taris dovaniers des divers ctats du globe et les modifications que ces tarifs subiront dans la suite.».

Não é de menor importancia a convenção de I 5 de Março de i 886 (4) para a creação de um

(2) Vid. E. Descamps, Les offices internationaux et leur avenir Bruxelles, I 894, p. I 4-- 16.

(3) Quem sabe si não suppunham ainda incluido aqui o Brasil?!

(4) Nesta, havida antes dos maleficios que nos trouxe a dictadura inilitar, figurou o Brasil. 
ureau encarregado do serviço das trocas, entre os ¿stàdos convencionarios, das seguintes publicações:

I. $\stackrel{\circ}{-}$ Documentos officiaes, parlamentares e adinistrativos publicados no logar de origem;

2. ${ }^{\circ}$ As obras publicadas por ordem e conta os governos.

O Instituto de Direito Internacional foi o primeiro, os diz ainda o Dr. Meili, que se fez ouvir acerca e quaes leis estrangeiras devem os Estados fazer reiproca communicação afim de se chegar a um reultado pratico, que para nós não será outro sinão a itura universalisação das normas juridicas.

- Quaes os meios de provar e fazer effectivas $\mathrm{s}$ leis estrangeiras perante os tribunaes dos differenss paizes?-Tal é, pondera o illustre professor, o ado pratico da questão.

Já em I.885 o Instituto fazia os seguintes votos, raduzidos em outras tantas conclusões, que alteradas aais tarde, no fundo ficaram sempre as mesmas:

«I. Que se obriguem os governos a se fazer reciroca communicação das leis, que estiverem em vigor que ulteriormente se promulgarem nos respectivos istados, conforme adiante se indica.

2. Que, entre as leis a communicar, comprehenem-se:

a) Os codigos, as leis e os regulamentos concernentes ao direito civil e commercial, o direito penal, o processo civil e o penal, inclusive o relativo á fallencia ou ao concurso de credores, e á organisação judiciaria. 


\section{$-148-$}

b) As leis e regulamentos que se referem ao direito administrativo, e publico interno, quando tiverem interesse geral para os Estados e para os cidadãos de diversas nações.

c) Os tratados, convenções e ajustes internacionaes, ou as respectivas disposições, concernentes ás relações de direito civil ou de interesse economico, abstracção feita das relações puramente politicas.

a) As leis e regulamentos expedidos em virtude dos ditos ajustes internacionaes, qualquer que seja a respectiva fórma, ou tratados de união com diversos Estados, ou convenções internacionaes especiaes com qualquer d'elles.

A estas cathegorias de actos poderá acrescentar outros a commissão de que trata o n. $3 .^{\circ}$

3. Uma commissão internacional permanente, composta de delegados nomeados pelos governos, será creada para o fim de receber os actos communicados, conserval-os e classifical-os systematicamente.

4. Por intermedio desta commissão será annualmente redigido, em francez, um quadro geral de todas as leis e actos communicados pelos diversos Estados, segundo a classificação acima indicada.».

Ainda o mesmo Instituto de Direito internacional, na sua sessão de Hamburgo (1891), tomou a seguinte resolução, endereçada ao Professor Rivier:

"L'Institut émét le vou qu' UNE UNION INTERNATIONALE SOIT FORMÉE $a u$ 
moyen d'un traité auquel seraient invités à adhérer tous les Eitats civilisés, en vue d'une publication aussi universelle, aussi prompte et aussi uniforme que possible DES TRAITÉs E'T CONVENITONS entre les Etats faisant partie de l. Union.»

E aquella missiva concluia assim: «Le conseil Édéral suisse, reconnaissant tous les services que pourait rendre une Union internationale pour la publicaion des traités et conventions entre les divers Etats, serait disposé à prendre l'initiative des démarches diplomatiques pour sa création.»

Ao mesmo tempo o rei da Belgica encarregou Rolin-Jacquemins de communicar ao Instituto que o seu governo tambem estava prompto a tomar a iniziativa em tão importante assumpto (5).

Finalmente, na sessão de Genebra (1 892), sobre exposição de Martens, o Instituto adoptou unanimemente dous largos e bem elaborados projectos sobre tão prolifico emprehendimento: o I. ${ }^{\circ}$ acerca da União internacional para a publicação dos tratados, o $2 .^{\circ}$ contendo o regulamento para a respectiva execução-os quaes foram enviados aos governos de diversos paizes pela notabilissima nota de 4 de Outubro daquelle anno, assim fechada:

«Sị, como esperamos, esta iniciativa fôr bem acolhida, teremos a honra e o prazer de convidar todos os paizes a se fazerem representar, no correr do anno proximo, em uma conferencia diplomatica, que se occupará da creaçã̀o da União e eventual organisação de seu bureaú.» XII, p. 228.

(5) Vid. Martens, Annuaire de l'Institut de droit intern. 1892-1894, 
Tendo sido favoraveis as respostas (6), foi convocada uma conferencia para 25 de Setembro de I 894 . em Berne.

Lê-se na nota da respectiva convocação:

«Le moment nous paraît venu aujourd' hui de convoquer cette confé. rence; en effet, aucun Gouvernement n'a contesté l'utilité ni l'importance de l'œuvre entreprise, et, si quelques hésitations ou divergences se sont produites au sujet de certaines dispositions de l'avant projet de l'Institut, elles nous ont fourni l'occasion de remanier cet-ãvant projet et d'offrir comme base de discussion et selon la promesse donnée dans la note du 4 octobre I 892 , le programme que nous joignons à la présente en plusieurs exemplaires. Ce programme, tout en étant suffisamment précis pour servir utilement aux travaux de la conférence, ne préjuge aucune des questions sur lesquelles des reserves ont pu être formulées. Il est d'ailleurs bien entendu que la participation à la délibération à laquelle nous venons vous convier n'implique aucune obligation pour l'avenir et que les Etats représentés resteront libres de discuter chacune des dispositions du projet qui sortira des travaux de la conférence.

(6) Entretanto, o «Standart» de 30 de Novembro de I 893 dá a seguinte injusta noticia: «The proposal made by Switzerland that an Internacional officeshould be established in Berne for the publication of all Internacional Treaties, protocols, etc., in their original languages, and with French translations if they are not in French, has been declined by most of the Powers, though the expense was estimated at only a hundred thousand francs a year.) 
C'est dans ce sens et dans l'espoir que, avec le bienveillant concours des hauts Gouvernements, il sera possibile d'aboutir à la création de l'Union projetée, que nous avons l'honneur d'inviter Votre Excellence à se faire représenter à la conférence qui se reunira à Berne.»

Naquella conferencia figuraram a Allemanha, a Republica Argentina, a Austria Hungria, a Belgica, o Congo, os Estados Unidos da America, a França, a Grecia, a Italia, a Liberia, os Paizes Baixos, Portugal, a Romania, a Russia, a Suissa, Tunis. Adheriram: a Bolivia, a Bulgaria, Costa Rica, Equador, Haitï, Honduras, Japão, Luxemburgo, o Estado livre de Orange, Paraguay, Persia, Sião, Transwal, Venezuela. O Brasil, a Dinamarca e o Mexico communicaram aguardar o resultado da conferencia.

N'aquella promptidão com que tantos estados acolheram a idéa do Instituto, vê o nosso auctor um acontecimento juridico da maior importancia.

Mas, inquire elle, qual foi o resultado pratico da conferencia?-Was war das praktische Ergebniss der Konferenz?

Infelizmente, negativo. Reunidos desde 25 de Setembro, a 3 de Outubro lavraram os delegados das diversas potencias o protocollo final dos respectivos trabalhos (Schlussprotokoll ou Procès-verbal final), em que se declararam sem poderes necessarios para se pronunciarem sobre o assumpto, entendendo, porém, em vista das discussões havidas, que se devia communicar aos diversos governos o relatorio dos trabalhos, documentos e deliberaçoes tomadas.

Esta ultima decisão bem mostra que a idéa não morreu; e que não morreu, mas ao contrario caminha, 
prova-o a circumstancia de já estar assentado que ainda este anno ou em 1896 haverá nova conferencia, com séde provavelmente em Berne (7), figurando no respectivo programma varios pontos do direito privado, notavelmente alguns ramos do direito commercial, como, por exemplo, a fallencia (8).

Não ha negal-o: de todas estas informações tira-se, a convicção inabalavel de que, de tal movimento internacional, só póde provir, em futuro mais ou menos proximo, a cosmopolisação do direito. A phrase de Lardy (9), phrase que já tem quasi vinte annos e é ora preconisada por Virgilio Rossel:- Qu'on le désire ou qu'on le regrette, le probleme de la cintralisation du droit civil s'impose d'une manière de jour en jour plus pressante-já não se enquadra apenas na accidentada moldura das montanhas helveticas; abre muito mais largo vôo, e' deixando como questão definitivamente vencida a ǹecessidade da unificação do direito nacional - apagadas, na unificação legislativa, até differenças locaes de casuismo idiosyncratico, como acontece nos cantões de Schwytz, Zurich, Vaud, e outros-vai recolhendo, por onde quer que palpite o sentimento da humanidade juridica, novas adhesões, novas forças,-

(7) Interessantissima foi a discussão levantada sobre a escolba do local e. da lingua para essa futura conferencia. Quanto ao local, disputaram a preferencia a Belgica e a Suissa; quanto á lingua, o francez, o allemão e* o inglez.

(8) Na segunda Conferencia de direito internacional privado, havida em Haia (Junho de I894), reservou-se este ponto para a alludida futura conferencia internacional-Actes da la deuxième Conférence de droit international privé (1894)-pag. I6 e I7.

(9) Les législations civiles des cantons suisses-Paris, I877. 
novos argumentos em pró da propaganda da nossa these, para se desfazerem um dia, ao calor da consciencia universal, variedades de linguas, nativismos inconsistentemente ciosos, exclusivismos estupidos de instituições e normas de caracteres anthropologica, biologica, psychologica, moral, juridica e economicamente cosmopolitas, como já se desfizeram cem, mil e mais variedades, que em outras espheras da actividade humana, tinham dividido os povos socialmente considerados.

O Imperio germanico, depois que a tenacidade unificadora, de Bismark, o Napoleão civil da segunda metade deste seculo, derrubou divisas politico-geographicas nas terras regadas pelo Rheno, pelo Danubio, pelo Elba; pelo Weser, a obra unificadora do direito começou a emparallelar-se com aquella, e hoje já se assignalam, como modelos da unidade legislativa germanica, o codigo do processo civil, a organisação judiciaria, o processo para o concurso de preferencias (Konkursversahren), o codigo penal, além de outras leis de menor importancia.

Muito antes mesmo da Constituição Imperial de I 6 de Abril de i 87 I, que reproduziu o art. $4 .^{\circ}$ n. I 3 da Constituição dos Estados da Allemanha do Norte, pélo qual se declarava materia federal o Direito das Obrigações, a Constituição de Francfort, do anno de ı 848, pugnava pela unidade da legislação civil para toda a Allemanha.

Com a Constituição de 187 , veiu a lei de 20 de Dezembro de I 873 , do Conselho. Federal, e modificando o citado art. $4 .^{\circ}$ n: ${ }^{\circ}$ I , declarou materia federal a totalidade do direito civil, o direito penal e todo o processo. Hoje, deste programma, só falta o Codigo civil, cujo projecto, devido ao concurso especial dos doctores Gohbard, von Kübel, Johow, Planck, 
e von Schmitt, já está concluido, e ora sujeito ao exame da commissão nomeada em i 89 I (10). A parte concernente ao Diveito das Obrigações, porém, já eștá promulgada,como lei federal.

Mas si este movimento, puramente local ou nacional, se deve menos a considerações e fins praticos, como pondera Ihering no seu Espirito do Direito romaño, do que á reacção operada nos espiritos e na sciencia tedesca contra a escola historica e a theoria do direito consuetudinario, que desde i 8 I4, com a influencia de Savigny, resistiam ás ideas, muito mais humanas, do seu antagonista Thibaut (I I), o. que é facto é, que esta mésma reacção não podemol-a, em ùltima analyse, emancipar da acção, quotidianamente impulsiva, da vida pratico-juridica. A escola historica já está contando os seus ultimos dias de vida precisamente porque, com este internacionalismo evolutivo das épochas correntes, desfizeram-se uns e foram arrancados outros, os marcos divisorios, que o genio de Savigny plantára como extremos da genesis do direito. $\mathrm{E}$ ha de ficar de todo vencida, porque o direito é a athmosphera moral das sociedades, comö o ar é condição vital dos homens-e o ar athmospherico, como envolucro externo deste planeta, percorre o mundo inteiro na sua homogeneidade transparente de massa gazosa.

Mesmo na Suissa, onde depois da adopção da Constituição federal de 29 de Maio de i 874, que extinguindo quasi totalmente a autonomia dos cantões em materia legislativa, firmou estreita centralisação, parecia estar exgottado o problemá da unificação do

(10). Vj. Projet de Cod. civ. allemand, traduit par de la Grasserie, Paris, 1893. Introd.

(I I) Emm. Gianturco, na Introd. ás Leggi civili della Germania, de Giulio Fioretti, p. XV. 
direito, como se exprime George Fazy (I 2), não parou ainda a guerra contra a escola historica. Não basta esta longa lista de instituições uniformes: capacidade civil, direito de estabelecimento, estado civil, casamento, commercio e transacçðes moveis, fallencia, propriedade litteraria e artistica, instrucção primaria, emissão e resgate de bilhetes bancarios, cultos e associações religiosas, caminhos de ferro, caça, pesca, trabalho das crianças nas manufacturas, casas de jogo e loterias, florestas, diques e outros trabalhos publicos, tarifas e impostos alfandegaes, pedagios, correios, telegraphos, etc., etc. (I.3); quer-se mais-- clama-se pelo direito helvetico, como todos os povos hão de um dia clamar pelo direito humano. O proprio Fazy, ha pouco citado, nervoso partidario da multiplicidade legislativa, fecha o seu opusculo com estas palavras: "l'unification du droit ne sera pas chez nous la victoire du droit germanique sur le droit romand, mais le triomphe de la vérité et de la justice.:

$\mathrm{Na}$ Inglaterra, a common law vai recebendo os mais profundos golpes, que the vibram os modernos bills e editos, inspirados nas recentes conquistas da actividade juridica internàcional, de modo que, no dizer de Buckle, aquella lei só tem de commum o nome; apagam-se, posto que lentamente, os typicos traços do cioso consuetudinarismo inglez, e consoante velha prophecia de Fortescue, vão se diluindo as_arrogancias exclusivistas da nobreza, estafado espolio dos reis e dos Senhores do Parlamento, e sobre os escombros dos normandos, dos Tudors e dos Stuarts, ergue-se o novo edificio do direito inglez moderno, por cujas portas e janellas, rasgadamente abertas, como nos dizia, 1890.

(12) La centralisation et l'unification du droit en Suisse-Genève nt. $x^{a}$.

(I3) Vid. Demombines, Les constitutions européennes, 2..$^{\circ}$ vol. pag. 304 
no anno de I889, em uma das salas da Advocate's Library, de Edimburgo, um dos mais intelligentes e sympathicos magistrados da formosissima capital escosseza, entram todas as regras de direito, que a experiencia dos povos haja proclamado victoriosas nessa eterna (e pela primeira vez ouvimos a phrase de Darwin em bocca britanica) nessa eterna STRUGGïE FOR LIFE.

$\mathrm{Na}$ flexibilidade actual da common law está, como diz Fazy, o seu principal merito; e neste merito está a razão do seu simultaneo dominio na monarchica Inglaterra e na democratica America; isto é, o tradicionalista inglez e o innovador americano vivem sob a mesma lei. Qual dos dous se renderá ao outro? A resposta já está escripta nos factos: as colonias inglezas, a Australia, a propria Grã Bretanha emancipam-se do tradicionalismo preterito, e entram francamente na conquista do direito por vir, que ha de ser o direito universal, a primeira das assonias humanas.

E a Hespanha, Portugal, Austria, Italia, mesmo a Russia, cada qual já uniformisou o seu direito privado, dando aos respectivos codigos a feição systematica de um todo, cujas linhas principaes dir-se-iam parallelas a correr no immenso plano da humanidade civilisada.

Ha dous mezes apenas que em França mais se accentuou a tendencia cosmopolisadora das relações juridicas. A 4 de Setembro, o ministro dos negocios estrangeiros, Mr. Hanotaux, abriu, na secretaria do seu ministerio, a conferencia periodica e geral do metro, communicando a adhesão do Japão (i 890), do Mexico (I89I) e de Tunis (Maio do anno corrente), e que a respectiva commissão da Camara dos Communs da Inglaterra propôz, em grande maioria, que dentro de dous annos seja ali substituida a immemorial jarda pelo moderno metro. 
«Esta ultima menção, disse o notavel ministro, é daquellas que attrahem a attenção do publico. Elle comprehende vagamente que a circumstancia que põe em presença diante de vós as duas medidas typos, de que se póde hoje dizer que occupão o mundo, marca a hora de um desses nobres combates da civilisação, em que a theoria e a pratica se encontram e procuram o exito de seus debates na harmonia e na concordia dos factos combinados pela razão superior de uma formula scientifica.

«Tal é, meus senhores, o alcance philosophico de nossos trabalhos. No espectaculo agitado da vida quotidiana, a perseverança com a qual trabalhais para vosso fim e os resultados obtidos, nos dão uma lição grande e fortificante, a saber: que o genio humano póde, na obscuridade das leis naturaes, desembaraçar certos dados immutaveis e inscrever no grande livro do progresso soluções definitivas» (I4).

E si uma só deve ser a medida da extensão physica do mundo, porque razão deverá ser multipla a medida da extensão moral dos povos, qual é o direito?

A I3 do mesmo mez de Setembro abriu-se em Bordeaux o Congresso Internacional da Imprensa, cujo programma encerra:

r. A discussão do projecto de união internacional das associações da imprensa.

2: A defesa da propriedade litteraria em materia de imprensa e de propriedade das informações.

$3 .^{\circ} \mathrm{O}$ estabelecimento de tarifas telegraphicas internacionaes.

(14). Do Jornal do Commercio. 


\section{$40^{\circ}$ O ensino profissional.}

Como se vê, em cada capitulo de tão vasto programma está latente mais uma força confraternisadora, sobre todas as quaes a mesma imprensa sö por si $e$ em si, como dizia Godefroy Cavaignac, em 1833 , na Camara dos deputados franceza, representa a sagrada hostia da communhão dos povos.

E si á unidade internacional do metro e da imprensa vier se juntar a unidade internacional das tarifas aduaneiras; mais a permuta internacional dos documentos a que se referiu a Convenção de is de Março de r 886, isto é, as publicáções de que os Estados convencionarios se obrigaram a fazer reciproca communicação, e são: os documentos officiaes, parlamentares e admiristrativos publicados no logar de origem e os trabalhos executados por ordem e conta dos governos; e mais decisivamente ainda sobre a solução do problema que nos occupa-a communicação official internacional dos codigos, leis e regulamentos concernentes ao direito civil, commercial e penal, e respectivos processos, á organisação judiciaria (I 5), ao direito administrativo e publico interno, aos tratados, convenções e ajustes internacionaes sobre relações de direito civil ou de interesse economico, abstracção feita só das relações puramente politicas-não parece certo, ou pelo menos provavel, que no

(15) No emtanto, a Constituição da novissima Republica brasileira, ao passo que manteve, e louvores sem numero lhe sejam por isso tributados, a unidade do direito material, conferiu a cada Estado a faculdade de legislar sobre o direito formal!' No Brasil póde o direito se vestir de tantos modos ou feitios quañtos são os Estados, sem contar o districto federal! Verdadeira folia carnávalesca.....

Afigura-se-nos tão grande o desacerto, que embora decidido partidario da unidade do direito, prefeririamos, com o illustre deputado Paranhos Montenegro (Discurso sobre a Unidade da Justiģa, proferido na sessâo de I6 de. Agosto ultimo), que aos Estados se confiasse tambem a confecção do direito: material. Haveria ao menos logica, e legislar sem logica é o mesmo que navegar sem bussola. A Constituinte esqueceu neste ponto a bussola. 
futuro o genero humano formará um só Estado comprehensivo de todas as nações, e no qual um direito unico, na phrase de Bluntschli, terá substituido a força, e os debates judiciarios as sangrentas luctas dos campos de batalha? (I6).

E si é certo que, como diz o Dr. Meili, só mediante o conhecimento universal das leis podem ser solvidos os conflictos de direitos, determinados pela separação dos homens por diversos Estados; si é aspiração commum o estabelecimento de um archivo onde o diplomata, o legislador, o juiz e o advogado, isto é, os mais activos operarios do direito, encontrem o texto authentico das leis do Estado, e assim legum custodiam habeantur; si é para lamentar a falta da publicação de todas as leis estrangeiras traduzidas, chronologica e systematicamente, em uma lingua universal-porque não haveremos de ser logicos, e concluir que melhor seria haver um direito só? Pois o ideal não deve ser antes a impossibilidade dos conflictos pela suppressão da disparidade das leis, em logar de alimental-os, tanto mais multiplicados quanto mais se facilitar a respectiva solução? Porque recuar diante do actual phenomeno politico, que dando a Pradier razão contra Pascoal Fiore, nos está convencendo a todos da fụtura assimilação dos povos na communhão scientifica e economica universal? Porque nos limitarmos a preconisar Story, que apenas julga possivel a universalisação de alguns principios juridicos, como os superiores de moral e justiça, os da legitima defesa, propriedade litteraria, commercio e outros, mas não - applaudir von Tienhoven quando, na ultima conferencia internacional de Haya, dizia que, menos do que a soberania do direito, vale a soberania das nações? Si já se estreitam, pelos laços do direito internacional

(16) Laurent, Dr. civ. intern., I. ${ }^{\circ}$ vol. pag. I3. 
publico, tantos grupos de variedade ethnica accentuada, que força invencivel obstará que um só direito aperte, como integração de um organismo somatico e psychico, todas as sociedades? A união faz a força: unam-se todos os povos no direito, porque este é a força de todas as forças. $\mathrm{Si}$ a biologia nos ensina, que a unidade de circulação vital é o que constitue o individuo, porque não nos ensinará a sociologia que a unidade do direito, essa circulação moral dos povos, é o que constitue a humanidade?

\section{Leiamos Novicow ( I 7 ):}

«Em resumo, a tribu e o estado são phases preparatorias--a nacionalidade é o organismo social chegado á consciencia e á maioridade completas. Nenhum progresso ulterior da associação humana é possivel antes que ella se tenha formado. A raça é uma concepção biologica mais do que sociologica, analoga á familia. O grupo de civilisação é uma sociedade de sociedades. Os que existem sobre a terra não possuem até hoje systema nervoso completo; são organismos em via de formação. Sua constituição definitiva não será possivel senão quando as nacionalidades componentes tiverem realisado completamente-tro sua unidade politica, e se houver formado um orgãó central, que em toda parte imporá a propria vontade.s

Pois bem: no futuro, que esta febril contemporanea renovação social vai a largos passos encurtando, não haverá grupos de civilisação, mas a civilisação humana, e com a unidade politica virá a universalisação legislativa, e o mundo inteiro se chamará à CosMOPOLIS DO DIREITÓ.

$$
\text { Dr. Ḟõ̃o Thonteiro. }
$$

S. Paulo, i. de Novembro de 1895 .

(17) La Polit. intern., pag. 136. 